\title{
Levels of PAHs and Potentially Toxic Metals in Three Species of Fresh and Smoked Fish Consumed in Lagos, Nigeria.
}

\author{
${ }^{1}$ Ayejuyo O. Olusegun, ${ }^{1}$ Obijiofor Richard and ${ }^{2}$ Osundiya M. Olubunmi \\ ${ }^{1}$ Chemistry Department, University of Lagos, Akoka. Nigeria \\ ${ }^{2}$ Chemistry Department Lagos State University, Ojo, Lagos. Nigeria
}

\begin{abstract}
Three samples of fish, Scomber japonica (titus), Sardinellaeba (sardine) and Merlucciuspolli (fresh stock fish) were collected from Ojo main market in Lagos. Two low molecular weight polycyclic aromatic hydrocarbons (naphthalene and anthracene) were determined using high performance liquid chromatography, (HPLC), after extraction with n-hexane by ultrasonication and clean up using SPE cartridges. Heavy metals were determined in the samples using atomic absorption spectrometer, (Perkin Elmer, Analyst 200) after digestion with aqua regia. The fat content was determined gravimetrically. The unsmoked samples had naphthalene range from $0.0788 \pm 0.0078 \mu \mathrm{g} / \mathrm{g}$ in Merlucciuspolli to $0.3845 \pm 0.0199 \mu \mathrm{g} / \mathrm{g}$ in Scomber japonica. Anthracene levels ranged from $0.4798 \pm 0.0072 \mu \mathrm{g} / \mathrm{g}$ in unsmoked samples of Merlucciuspolli to $1.2254 \pm 0.0071$ $\mu \mathrm{g} / \mathrm{g}$ in Scomber japonica. The low fat containing specie (Merlucciuspolli) accumulated PAHs over the smoking periods, while a decrease was observed in the high fat containing species (Scomber japonica and Sardinellaeba). The highest concentration of $\mathrm{Pb}(8.65 \mu \mathrm{g} / \mathrm{g}), \mathrm{Cu}(9.53 \mu \mathrm{g} / \mathrm{g}), \mathrm{Fe}(201.80 \mu \mathrm{g} / \mathrm{g})$ and $\mathrm{Zn}(122.15$ $\mu \mathrm{g} / \mathrm{g}$ ) in the unsmoked fishes were found in unsmoked Scomber japonica while the highest concentration of $\mathrm{Cr}$ $(13.68 \mu \mathrm{g} / \mathrm{g})$ and $\mathrm{Ni}(5.88 \mu \mathrm{g} / \mathrm{g})$ in the fishes were found in the unsmoked Merlucciuspolli. Cadmium was not detected in all the samples. The low fat containing specie showed increase in heavy metals over the smoking periods, while the high fat containing species also accumulated these heavy metals at 1 hour smoking period, but a decrease was noted over the 2 hours and 3 hours smoking periods. Smoking has effect on the level of these toxicants, as PAHs and heavy metals tend to accumulate on smoking. Smoking appeared to influence toxicants levels the fishes. Levels of the PAHs were higher than the regulatory permissible limits of the World Health Organization. Levels of the toxic metals were within the WHO set permissible limits except for $\mathrm{Pb}$ (in unsmoked Scomber japonica), Fe (in Sardinellaeba smoked for 1 and 2 hours, and in Merlucciuspolli smoked for 2 and 3 hours) and $\mathrm{Cr}$ (in all the samples).
\end{abstract}

Keywords: Toxicants, smoked and unsmoked fish, ultrasonication, SPE, HPLC.

\section{Introduction}

There is an increasing concern about the quality of foods in several parts of the world. The studies of toxicology and environment have interest in the determination of toxic substances in food. Food safety implies absence or acceptable and safe levels of contaminants, adulterants, naturally occurring toxins or any other substance that may make food injurious to health on an acute or chronic basis. Food quality can be considered as a complex characteristic of food that determines its value or acceptability to consumers. Besides safety, quality attributes include nutritional value, organoleptic properties such as appearance, colour, texture, taste and functional properties [1]

Food can become contaminated during thermal treatments that occur in processes of food preparation and manufacture (drying and smoking) and (roasting, baking, and frying) [2]. Human exposure to PAHs and heavy metals occurs in three ways: inhalation, dermal contact and consumption of contaminated foods. Polynuclear aromatic hydrocarbons are found in substantial quantities in some foods, depending on the mode of cooking, preservation and storage, and are detected in a wide range of matrices; meats, fishes, vegetables and fruits.

Diet is the major source of human exposure to these toxicants as it accounts for 88 to $98 \%$ of such contamination [3]. Processing of food at high temperatures (grilling, roasting, frying and smoking) are major sources generating PAHs. Levels as high as $200 \mu \mathrm{g} / \mathrm{kg}$ have been found for individual PAHs in smoked fish and meat samples. For instance, in barbecued meat, $130 \mu \mathrm{g} / \mathrm{kg}$ has been reported whereas the average background values are usually in the range of 0.01 to $1 \mu \mathrm{g} / \mathrm{kg}$ in uncooked foods [4].

Polycyclic aromatic hydrocarbons (PAHs) and heavy metals have been known to be environmental contaminants for decades and several monitoring programmes have been conducted to estimate the pollution of soil, water, biota and air by PAHs and heavy metals. Since emissions are not limited to national territories, international standards and guidelines have been set in order to gain relevant, comparable data as a basis for sound decision-making. Contribution of fish to the daily dietary energy supply is very important. World wide, fish is considered to be an essential part of the diet [5]. 
Fish is widely consumed in many parts of the world by humans because it has high protein content, low saturated fat and also contains omega-3 fatty acids known to support good health [6]. The safety issues related to the possibility of heavy metals and some polycyclic aromatic hydrocarbons are of concern. The subject of heavy metals and polycyclic aromatic hydrocarbons is receiving increasing popularity in food industry due to increasing incidents of contamination in agriculture and seafood sources. Apart from the threat from polluted environment, smoked food is subjected to heavy metals and polycyclic aromatic hydrocarbons contamination during the smoking process. The ingestion of food is an obvious means of exposure to metals [7].

Smoked fish is one of the delicacies enjoyed by Nigerians. Fish is smoked, traditionally in order to preserve and facilitate easy transportation from fishing ports to other parts of the country [8].

\section{Materials And Method}

Sampling, preparation and smoking of fish.

The fish samples, Scomber japonica, Sardinellaeba and Merlucciuspolli were purchased from selected sales depots in Ojo main market, Lagos, Nigeria. The collected samples species were, however, identified by the Department of Marine Biology and Fisheries, University of Lagos, Akoka, Lagos State, Nigeria. Species used for control were fresh fishes.

The fish samples were smoked for 1 hour, 2 hours and 3 hours after which they were dried to constant weight in oven at $105^{\circ} \mathrm{C}$ for 10 hours. The edible muscles of the fishes were separated from the whole fish samples and were then blended with blender and kept in air tight containers prior to extraction process[8].

\section{Fat content determination}

Approximately $2.0 \mathrm{~g}$ of each pulverized samples was carefully transferred into the extraction thimble and placed in the extraction chamber of the Soxhlet extraction unit. The unit consisted of a $250 \mathrm{ml}$ round bottom flask, condenser and extraction tube, well seated in heating mantle with wide temperature range. Soxhlet extraction of the samples was carried out with $50 \mathrm{ml}$ chloroform and $50 \mathrm{ml}$ methanol at $50^{\circ} \mathrm{C}$ for 2 hours. The extract was transferred into weighing crucibles and allowed to dry in a fume cupboard. The difference in weights between the empty crucible and the extract contained crucible was taken as the fat content [9].

\section{Naphthalene and anthracene extraction}

For the determination of the naphthalene and anthracene content, approximately $5.0 \mathrm{~g}$ of each type of smoked and dried fish was weighed into amber bottles and extracted sequentially by ultrasonication using $25 \mathrm{ml}$ of $\mathrm{n}$-hexane for 1 hour. After ultrasonication the supernatant was decanted into a vial and $15 \mathrm{ml}$ of fresh solvent was added for another 1 hour of ultrasonication. The process was repeated with another $10 \mathrm{ml}$ of fresh solvent for 1 hour. The combined extracts $(50 \mathrm{ml})$ were centrifuged at $2500 \mathrm{rpm}$ for 10 minutes and the supernatant was decanted [10].

\section{Clean - up and Separation}

The pooled $50 \mathrm{ml}$ supernatant was cleaned-up using Whatman nylon filter membrane. Further clean-up was done using the solid phase extraction (SPE) cartridges. The sorbent of the SPE cartridges were first conditioned with n-hexane, after which the filtered extracts were loaded on to the cartridges, the analytes were eluted with dichloromethane. The volume of the dichloromethane was reduced to dryness and the extract was then reconstituted in $200 \mu$ of acetonitrile [9].

\section{Sample analysis}

Stock standard solutions $(1000 \mu \mathrm{g} / \mathrm{ml})$ were prepared from pure standard materials. Four different concentrations $(5,10,25$ and $50 \mu \mathrm{g} / \mathrm{ml})$ of naphthalene and $(1,5,10$ and $20 \mu \mathrm{g} / \mathrm{ml})$ of anthracene were prepared from the stock solution and made to volume with acetonitrile.

A $5 \mu$ aliquot of each of the standard solutions was injected into the HPLC using a constant volume injection loop while maintaining the same HPLC condition (MP: 0.1\% $\mathrm{H}_{3} \mathrm{PO}_{4}$ : Acetonitrile, 5:95, Flow rate: $1 \mathrm{ml} / \mathrm{min}$, Temp.: ambient, Wavelength: $216 \mathrm{~nm}$ ) as used for the samples. The volume injected to the nearest 0.1 $\mu \mathrm{l}$ and the resulting peak size area units were recorded. Sample blank was similarly treated to demonstrate that interferences from the analytical system and glassware were taken into reckoning. A performance record was maintained to document the quality of data generated.

A $5 \mu \mathrm{l}$ aliquot of each of the sample extract was then injected into the HPLC maintaining the same condition as above. The resulting peak size area units were recorded. The HPLC column was re-equilibrated for at least 10 minutes between injections. Duplicate analysis was conducted for every sample to ascertain precision and accuracy. The concentrations of the analytes in the samples were then calculated from calibration curves prepared. 
Digestion procedure of sample

\section{Heavy Metals}

A $2.0 \mathrm{~g}$ of the dried and pulverized edible muscle of the fish samples was weighed into a $100 \mathrm{ml}$ kjeldahl flask, which was cleaned by boiling in a diluted (2-fold) aqua regia for 8 hours. A $20 \mathrm{ml}$ portion of aqua regia was added to the muscle sample and they were heated on an aluminum heating block at $190^{\circ} \mathrm{C}$ for 2 hours. The digests were allowed to cool and were filtered into $50 \mathrm{ml}$ volumetric flasks and were made up to mark with distilled water. The resulting sample solutions were subjected to the atomic absorption spectroscopic (AAS) measurements and the results were given as $\mu \mathrm{g} / \mathrm{g}$ dry weight. Data obtained from the experiment were statistically treated.

IV. Results and Discussion

Table 1.Fat contents of fishes used for the study.

\begin{tabular}{llll}
\hline Scientific name & Code & Common name & Fat content (mg/g) \\
\hline Scomber japonica & SJ & Titus & $35.678 \pm 0.264$ \\
Sardinellaeba & SE & Sardine & $21.097 \pm 0.437$ \\
Merlucciuspolli & MP & Fresh stock fish & $4.422 \pm 0.351$ \\
\hline
\end{tabular}

Table 2.Mean concentrations $(\mu \mathrm{g} / \mathrm{g})$ of naphthalene and anthracene in edible muscles of unsmoked and smoked fishes.

\begin{tabular}{lll}
\hline & Naphthalene & Anthracene \\
\hline SJ & $0.3845 \pm 0.0199$ & $1.2254 \pm 0.0071$ \\
SE & $0.2378 \pm 0.0107$ & $0.5692 \pm 0.0112$ \\
MP & $0.0788 \pm 0.0078$ & $0.4798 \pm 0.0072$ \\
SJS1 & $0.2627 \pm 0.0462$ & $0.4541 \pm 0.0659$ \\
SJS2 & $0.1864 \pm 0.0109$ & $0.4184 \pm 0.0059$ \\
SJS3 & $0.0459 \pm 0.0239$ & $0.1625 \pm 0.0185$ \\
SES1 & $0.3452 \pm 0.0034$ & $0.4532 \pm 0.0231$ \\
SES2 & $0.2478 \pm 0.0003$ & $0.4232 \pm 0.0215$ \\
SES3 & ND & $0.2298 \pm 0.0011$ \\
MPS1 & $0.4465 \pm 0.0362$ & ND \\
MPS2 & $0.6372 \pm 0.0546$ & $0.1987 \pm 0.0167$ \\
MPS3 & $0.6849 \pm 0.0007$ & $0.4474 \pm 0.0881$ \\
\hline
\end{tabular}

ND- not detected SJ- Scomber japonica, SE- Sardinellaeba, MP- Merlucciuspolli, SJS1,SJS2 and SJS3smoked Scomber japonica for $1 \mathrm{hr} ., 2 \mathrm{hrs}$. and $3 \mathrm{hrs}$., respectively, SES1,SES2 and SES3- smoked Sardinellaeba for $1 \mathrm{hr}$., $2 \mathrm{hrs}$.and $3 \mathrm{hrs}$.Respectively, MPS1, MPS2 and MPS3- smoked Merlucciuspolli for $1 \mathrm{hr}$., $2 \mathrm{hrs}$.and 3 hrs.respectively.

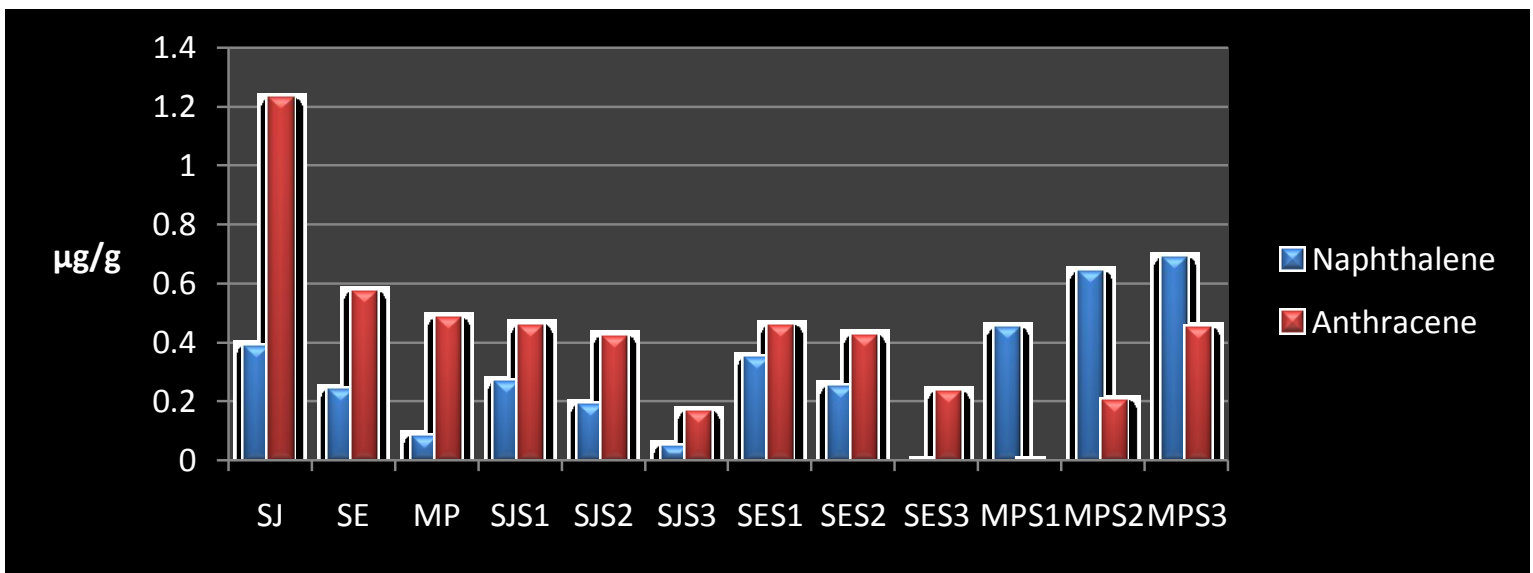

Fig.1. Naphthalene and anthracene contents $(\mu \mathrm{g} / \mathrm{g})$ in unsmoked and smoked fishes for different smoking periods.

The unsmoked samples had naphthalene ranged from $0.0788 \pm 0.0078 \mu \mathrm{g} / \mathrm{g}$ in Merlucciuspolli to $0.3845 \pm 0.0199 \mu \mathrm{g} / \mathrm{g}$ in Scomber japonica, while anthracene ranged from $0.4798 \pm 0.0072 \mu \mathrm{g} / \mathrm{g}$ (Merlucciuspolli) to $1.2254 \pm 0.0071 \mu \mathrm{g} / \mathrm{g}$ (Scomber japonica) of the unsmoked fish samples. The low fat containing specie (Merlucciuspolli) accumulated naphthalene and anthracene over the smoking periods, while a decrease was observed in the high fat containing species (Scomber japonica and Sardinellaeba).

The high concentration of these hydrocarbons in Scomber japonica and Sardinellaeba (unsmoked) could be attributed to the high fat content of the species as was earlier observed by Knize et al [11 in their work. 
The decrease in the concentration of these hydrocarbons in Scomber japonica and Sardinellaeba over the smoking periods could be understood to be due to high loss of fat from these species on smoking, because PAHs are believed to be absorbed and more concentrated in fatty tissues and adsorbed on the samples upon smoking. The increase in the concentration of these low molecular weight hydrocarbons in Merlucciuspolli over the smoking periods can be suggested to have been influenced by low fat and pyrolysis resulting from melted fat dropping onto the heat source [12].

Since the maximum allowable limit for PAHs in drinking water of man (which is also a consumable like food) is $0.0002 \mathrm{ppm}$ [13], the current study therefore reveals much higher concentration in the samples. This therefore places the several consumers at potential health risk. However, this study reveals low levels of naphthalene when compared with the findings of the Agency for Toxic Substances and Diseases Registry(ASDTR)[14] and EPA also has suggested that taking into the body $0.3 \mathrm{mg} / \mathrm{kg}$ body weight of anthracene each day is not likely to cause any significant (noncancerous) harmful health effects.

Table 3.Heavy metals concentration $(\mu \mathrm{g} / \mathrm{g})$ in unsmoked and smoked fishes.

\begin{tabular}{lllllllllllllll}
\hline & SJ & SE & MP & SJS1 & SJS2 & SJS3 & SES1 & SES2 & SES3 & MPS1 & MPS2 & MPS3 & $\begin{array}{c}\text { WHO } \\
\text { limit }\end{array}$ \\
\hline $\mathbf{C d}$ & ND & ND & ND & ND & ND & ND & ND & ND & ND & ND & ND & ND & 0.2 \\
$\mathbf{C r}$ & 8.25 & 13.08 & 13.68 & 16.73 & 14.93 & 13.03 & 15.25 & 15.05 & 11.45 & 17.13 & 18.38 & 22.55 & 5 \\
$\mathbf{C u}$ & 9.53 & 6.13 & 4.25 & 7.93 & 5.88 & 2.38 & 9.50 & 5.75 & 2.90 & 4.80 & 4.90 & 5.68 & 100 \\
$\mathbf{F e}$ & 201.80 & 185.83 & 126.15 & 292.50 & 242.55 & 176.20 & 408.25 & 333.75 & 228.28 & 300.00 & 339.00 & 364.75 & 300 \\
& & & & & & & & & & & & & \\
$\mathbf{N i}$ & 0.30 & 4.18 & 5.88 & 4.93 & 3.83 & 3.43 & 3.08 & 2.63 & 0.50 & 2.00 & 4.98 & 5.15 & 80 \\
$\mathbf{P b}$ & 8.65 & 3.48 & 1.73 & 4.75 & 0.68 & 0.55 & 0.50 & 3.95 & 3.45 & ND & 2.20 & 2.78 & 5 \\
$\mathbf{Z n}$ & 122.15 & 103.93 & 100.58 & 158.25 & 139.23 & 122.70 & 162.43 & 144.70 & 135.33 & 100.98 & 147.70 & 158.03 & 500 \\
\hline
\end{tabular}

ND- not detected SJ- Scomber japonica, SE- Sardinellaeba, MP- Merlucciuspolli, SJS1, SJS2 and SJS3- smoked Scomber japonica for $1 \mathrm{hr} ., 2 \mathrm{hrs}$. and $3 \mathrm{hrs}$., respectively, SES1,SES2 and SES3- smoked Sardinellaeba for $1 \mathrm{hr} ., 2 \mathrm{hrs}$. and $3 \mathrm{hrs}$., MPS1, MPS2 and MPS3- smoked Merlucciuspolli for $1 \mathrm{hr} ., 2 \mathrm{hrs}$. and 3 hrs. respectively.

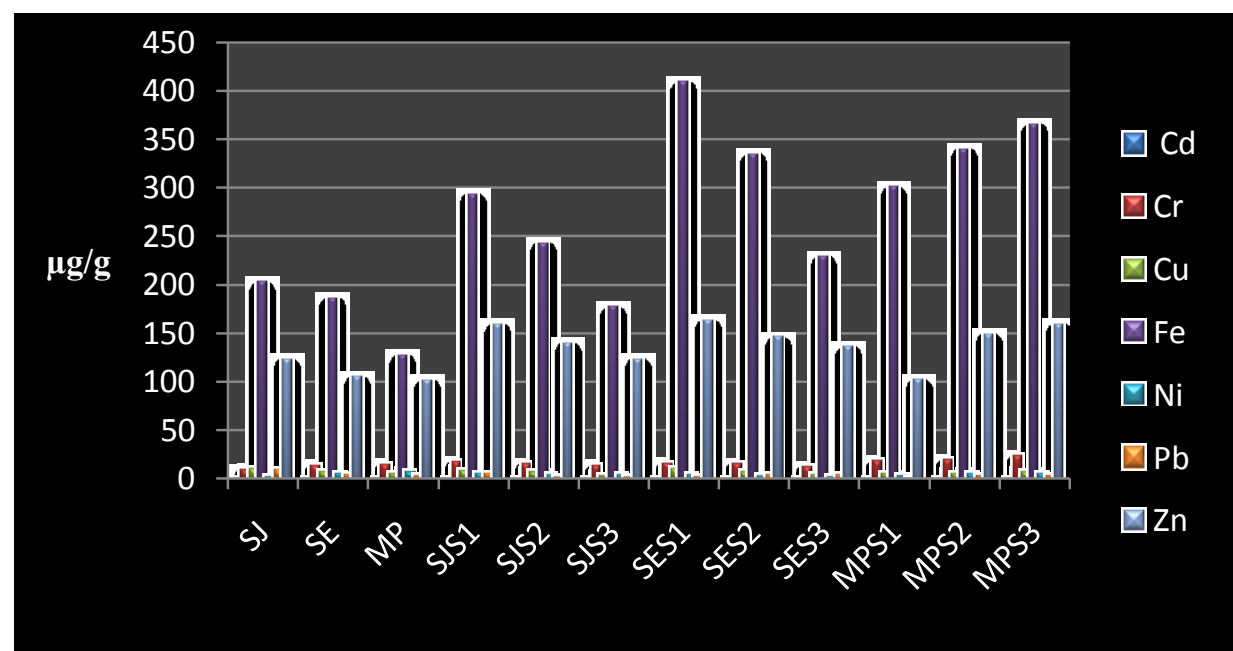

Fig. 2.Heavy metals content $(\mu \mathrm{g} / \mathrm{g})$ in the edible muscle of unsmoked and smoked fishes 


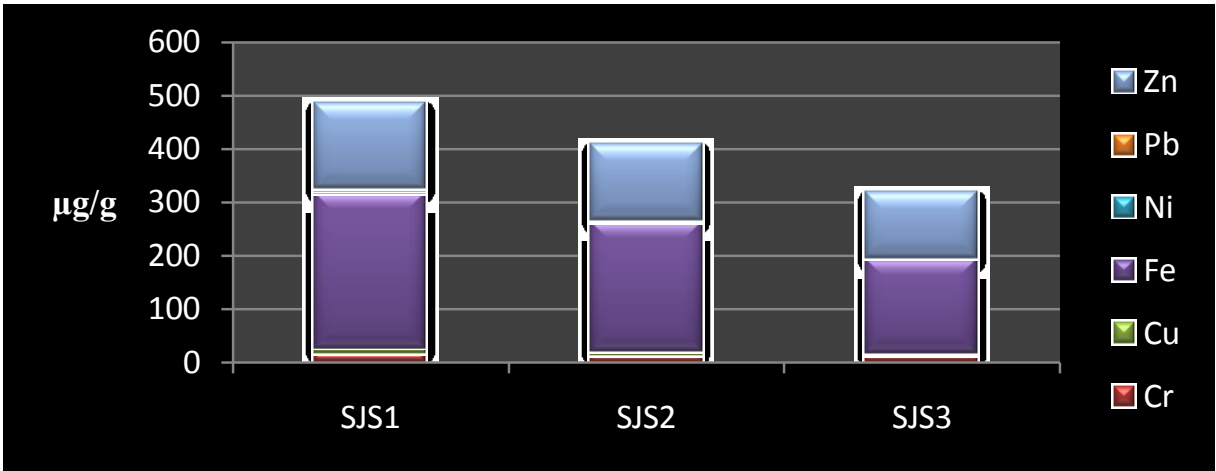

Fig. 3.Comparison of total heavy metals content $(\mu \mathrm{g} / \mathrm{g})$ in smoked Scomber japonica at different smoking periods.

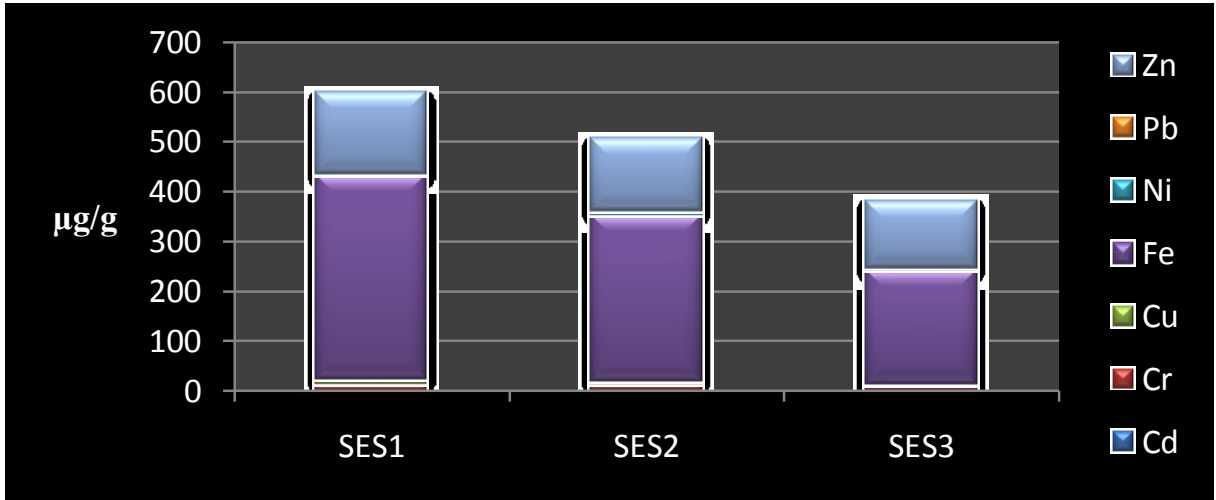

Fig. 4.Comparison of total heavy metals content $(\mu \mathrm{g} / \mathrm{g})$ in smoked Sardinellaeba at different smoking periods.

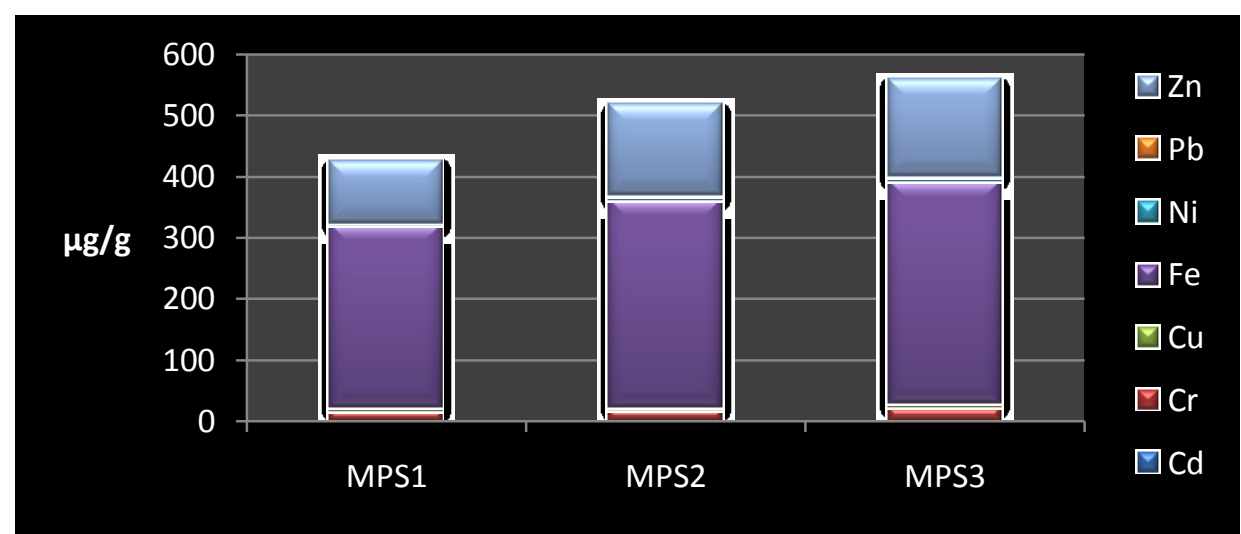

Fig. 5.Comparison of total heavy metals content $(\mu \mathrm{g} / \mathrm{g})$ found in smoked Merlucciuspolli at different smoking periods.

The goal of the digestion process was the complete solution of the analytes and the complete decomposition of the solid (matrix) while avoiding loss or contamination of the analyte. The highest concentration of $\mathrm{Pb}(8.65 \mu \mathrm{g} / \mathrm{g}), \mathrm{Cu}(9.53 \mu \mathrm{g} / \mathrm{g}), \mathrm{Fe}(201.80 \mu \mathrm{g} / \mathrm{g})$ and $\mathrm{Zn}(122.15 \mu \mathrm{g} / \mathrm{g})$ were determined in unsmoked Scomber japonica while the highest concentration level of $\mathrm{Cr}(13.68 \mu \mathrm{g} / \mathrm{g})$ and $\mathrm{Ni}(5.88 \mu \mathrm{g} / \mathrm{g})$ were also found in the unsmoked Merlucciuspolli. Cadmium was not detected in all samples. The low fat containing specie showed increase in heavy metals concentrations at 1 hour smoking period, but a decrease was noted over the 2 hours and 3 hours smoking periods as shown in fig. 5.

The high concentration of these metals in Scomber japonica and Sardinellaeba (unsmoked) could be due to high fat content of the fishes, as these metals tend to accumulate in fatty tissues of fishes based on the availability in the environment of its imports. The decrease in the concentration levels of these in Scomber japonica and Sardinellaeba over the 1 hour to 3 hours smoking time can be clearly linked with the uncontrollable drainage of fat upon smoking, thereby having a great reduction in heavy metals than are accumulated on their surfaces upon smoking. While the low fat containing specie (Merlucciuspolli) experienced 
increase in heavy metal concentration levels over the 1 hour to 3 hours smoking period. This might be attributed to more loss of water than fat drainage on smoking.

\section{Conclusion And Recommendations}

It can be reasonably concluded that the concentration of these toxicants are dependent on three factors, which are, the fat content, smoking duration and pyrolysis resulting from melted fat (for PAHs). The high level of these toxicants in unsmoked Scomber japonica and Sardinellaeba confirms the fact that these toxicants accumulate in fatty tissues, as it was observed that the more the fat content the higher the concentration of toxicants. Smoking, generally was understood to add to the increase in concentration of these toxicants in the fishes, but also dependent on their fat contents. The more fat containing species (Scomber japonica and Sardinellaeba) dropped more fat than it accumulated on smoking, while the low fat containing specie (Merlucciuspolli) concentrated the toxicants upon smoking. Smoking appeared to influence toxicant levels in the fishes, and this could be a source of heavy metal poisoning in the environment. Levels of the PAHs were higher than regulatory permissible limit set by the World Health Organization in food, but low when compared with the findings of ATSDR in August, 2005. Levels of the heavy metals were within the WHO set permissible limit except for $\mathrm{Pb}$ (in unsmoked Scomber japonica), Fe (in Sardinellaeba smoked for 1 and 2 hours, and in Merlucciuspolli smoked for 2 and 3 hours) and $\mathrm{Cr}$ (in all the samples).

\section{References}

[1]. World Health Organization (WHO) (1998). Selected non-heterocyclic polycyclic aromatic hydrocarbons. Environmental Health Criteria 202, World Health Organization, Geneva

[2]. Ishizaki, A., Saitoa, K.,Haniokab, N., Narimatsub, S. andKataokaa, H.(2010).Determination of polycyclic aromatic hydrocarbons in food samples by automated on-line in-tube solid-phase microextraction coupled with high-performance liquid chromatography-fluorescence detection.J. Chromatogr., 1217: 5555-5563.

[3]. Farhadian, A., Jinap, S., Hanifah, H.N. and Zaidul, I.S. (2011).Effects of meat preheating and wrapping on the levels of polycyclic aromatic hydrocarbons in charcoal-grilled meat. Food Chem., pp. 141-146.

[4]. Gómez-Guillén, M.C., Gómez-Estaca, J., Giménez, B. and Montero, P. (2009). Alternative fish species for cold-smoking process. Int. J. Food Sci. Technol., 44: 1525-1535.

[5]. Food and Agriculture Organization, (FAO) (2006). The state of world fisheries and aquaculture. Food and Agriculture Organization of the United Nations, Rome. p142.

[6]. USEPA, (2004). Microwave assisted acid digestion of sediments, sludge, soils and oils, test methods of evaluating solid waste ( $3^{\text {rd }}$ ed., $3^{\text {rd }}$ update; SW-846 Method 3051), U.S. Environmental Protection Agency, Washington, DC.

[7]. Voegborlo, A.B., El-Methnani, A.M. and Abedin, M.Z. (1999). Mercury, cadmium and lead content of canned tuna fish, Food Chemistry 67, 341-345.

[8]. Olabemiwo, O.M., Alade, A.O., Tella, A.C. and Adeniran, G.O. (2007). Assessment of Polycyclic aromatic hydrocarbons content in smoked C. gariepinus and T. guineensis fish species available in Western Nigeria. International journal of Basic and sciences, 11(2): 135-145

[9]. Silva, B.O., Adetunde, I.T., Oluseyi, T.O., Olayinka, K.O. and Alo, B.I. (2011). Effects of the methods of smoking on the levels of polycyclic aromatic hydrocarbons (PAHs) in some locally consumed fishes in Nigeria. African Journal of Food Science, 5(7): 384-391.

[10]. Garcia- Falcon, M.S.G., Amigo, G.S., LMA, Y., Villaizan, M.J. and Lozano, S.L. (1996). Enrichment of benzo(a)pyrene in smoked food products and determination by high-performance liquid chromatography fluorescence. J. chromatogram., 753: 207215.

[11]. Knize, M.G., Salmon, C.P., Oais, P. and Felton, S.S. (1999).Food heating and the formation of heterocyclic aromatic amine and $\mathrm{PAH}$ mutagens/carcinogens.

[12]. World Health Organization (WHO) (1997). Recommended limit for metals in finfish. Environmental health, Criteria No 70. Principles for safety and assignment of food additive and contamination in food. Technical Report Series 505, Geneva. p309.

[13]. World Health Organization (WHO) (1984).Guidelines for Drinking Water Quality. Geneva

[14]. Agency for Toxic Substances and Diseases Registry (2005).Toxicology profile for naphthalene and 1-methylnaphthalene, 2 methylnaphthalene. Atlanta, GA: U.S. Department of Health and Human Services, Agency for Toxic Substances and Diseases Registry. 